\title{
Two-warehouse inventory model of deteriorating items with three-component demand rate and time-proportional backlogging rate in fuzzy environment
}

\author{
Neeraj Kumar ${ }^{a}$, S. R. Singh ${ }^{\text {b }}$ and Rachna Kumari
}

\author{
${ }^{a}$ Department of Applied Science, IIMT Engineering College, Meerut, India \\ ${ }^{b}$ Department of Mathematics, D.N. College, Meerut., India \\ ${ }^{c}$ Department of Mathematics, Meerut College, Meerut.

\section{H R O N I C L E} \\ A B S T R A C T
}

\section{Article history:}

Received March 162013

Received in revised format

May 92013

Accepted May 92013

Available online

May 102013

Keywords:

Inventory management

Three component demand

Fuzzy

\begin{abstract}
A finite time horizon inventory problem for a deteriorating item having two separate warehouses, one with an own warehouse (OW) of finite dimension and the other with a rented warehouse $(\mathrm{RW})$, is developed in fuzzy environment. Due to different preserving facilities and storage environment, inventory holding cost is considered to be different in different warehouses. The demand rate of item depends on the selling price and is displayed stocked level in own warehouse. Shortages are allowed and backlogged them partially, which depends on the duration of stock out. The stocks of RW are transported to OW in continuous release pattern. Due to impreciseness in nature, total revenue and shortage cost are assumed to be imprecise in nature too. By using the fuzzy goal programming method, multi-objective problem is converted into single objective function. The model is illustrated numerically and the results are presented in tabular form.
\end{abstract}

(C) 2013 Growing Science Ltd. All rights reserved

\section{Introduction}

Marketing researchers and practitioners have long recognized that demand of many retail items is proportional to the amount of inventory displayed (Fathollah Bayati et al., 2011; Taleizadeh et al., 2012). According to Levin et al. (1972) "at times, the presence of inventory has a motivational effect on the people around it. It is a common belief that large piles of goods displayed in the departmental store will lead the customer to be more." Gupta and Vrat (1986) were the first to build up models for stock-dependent consumption rate. Mandal and Phaujdar (1989) after that developed an economic production quantity model for deteriorating items with constant production rate and linearly stockdependent demand. Some of the recent works in this region may relate to Datta et al. (1998), Dye (2002), Dye and Ouyang (2005), etc. Singh et al. (2010) presented an inventory model with stockdependent demand with two shops of a single management. Recently, Muluneh and Rao (2012) developed an EPQ models for deteriorating items with stock-dependent production rate. 
In the competitive market situation, it is commonly observed that an increase in shelf space and glamorous display for an item induce more consumers to buy it. Dye and Ouyang (2005) investigated an economic order quantity (EOQ) model for perishable items under stock-dependent selling rate and time-dependent partial backlogging. In two-component demand, it is assumed that the demand rate is stock-dependent down to a certain level and then it becomes constant. However, it is commonly observed that the rate will not be dependent on displayed stock level for a huge amount of stock as all available stock cannot be displayed properly and glamorously because of cost of modern light, electronic arrangement and space will be increased (e.g. fashionable goods shop). It depends on displayed stock level within a range and beyond this range it will be quite uniform. This type of demand rate is called three-component demand rate.

It has been recognized that one's ability to make precise statement concerning an inventory model diminishes with increasing complexities of the system. Generally, it may not be possible to define the objective goals, precisely. In reality, management is most likely to be uncertain of the true value of parameters because of many unforeseen incidents like strike, hike in wages, increased transportation cost etc. Hence, during the course of business, a vendor or decision marker is forced to settle down with a lower profit amount compared to the profit as he/she normally has targeted due to adverse situation. Moreover, shortages bring loss of goodwill for the vendor, which cannot be measured, numerically. For this reason, it is advisable to restrict the shortages as much as possible to minimize the loss of goodwill. Therefore, we may conclude that it is difficult to determine the exact amount of profit and shortage cost. Under these phenomena, the inventory model may be better treated in a fuzzy system. Moreover, shortages bring loss of goodwill for the vendor, which cannot be measured, numerically. For this reason, it is advisable to restrict the shortages as much as possible. From the above discussion, we may conclude that it is difficult to determine the exact amount of profit and shortage cost rather a range may be fixed for these. Hence, under these phenomena, the inventory model may be better treated in a fuzzy system.

In many cases, customers are conditioned to a shipping delay, and may be willing to wait for a short time in order to get their first choice. Generally speaking, the length of the waiting time for the next replenishment is the main factor for deciding whether the backlogging will be accepted or not. The willingness of a customer to wait for backlogging during a shortage period declines with the length of the waiting time. Therefore, a situation is quite likely to arise where many savvy retailers suggest replacement items, and provide the restocking date to allow the customer to wait during the stock out period. To reflect this phenomenon, Abad $(1996,2001)$ discussed a pricing and lot-sizing problem for a product with a variable rate of deterioration and partial backlogging. The backlogging rate depends on the time to replenishment - the longer customers must wait, the greater the fraction of lost sales. However, he does not use the stock-out cost (includes backorder cost and the lost sale cost) in the formulation of the objective function since these costs are not easy to estimate, and its immediate impact is that there is a lower service level to customers.

In classical inventory models, organizations own a single warehouse without ability limitation. In practice, while a large stock is to be apprehended due to the restricted capacity of the owned warehouse $(\mathrm{OW})$, one extra warehouse is required. This extra warehouse may be a rented warehouse (RW), which is assumed to be available with unlimited capacity. There exist some practical reasons such that the organizations are motivated to order more items than the capacity of OW. For example, the price discount for bulk purchase may be advantageous to the management; the demand of items may be high enough such that a considerable increase in profit is expected; and so on. In these situations, it is generally assumed that the holding cost in OW is less than that in RW. To reduce the inventory costs, it will be economical to consume the goods of RW at the earliest. The stocks of OW will not be released until the stocks of RW are exhausted. 
The problems on classical inventory models found in the existing literature generally deal with single storage facility. However, when the optimal lot size dictated by the EOQ model becomes more than the total amount that can be stored in the existing storage facility (Warehouse owned by the management $\mathrm{OW}$ ) the question of acquiring some extra storage facility to store these excess quantity arises. This additional storage facility may be a RW with sophisticated preservation facility and abundant space. Hartley (1976) first developed such inventory model with double storage facility OW and RW. After his pioneering contribution, several other researchers have attempted to extend his work to various other realistic situations.

In this connection, mention may be made of the studies undertaken by Sarma (1983). In this study, he developed a deterministic inventory model with finite replenishment rate with two-storage facility; Dave (1988) further discussed the cases of bulk release pattern for both finite and infinite replenishments. He rectified the errors in Murdeshwar and Sathe (1985) and gave a complete solution for the model given by Sarma (1987). In the above literature, deterioration phenomenon was not taken into account. Assuming the deterioration in both warehouses, Sarma (1987), extended his earlier model to the case of infinite replenishment rate with shortages. Pakkala and Achary (1992-a, 1992-b) unmitigated the two-warehouse inventory model for deteriorating items with finite replenishment rate and shortages. In these models mentioned above the demand rate was assumed to be constant. Subsequently, the ideas of time dependent demand and stock dependent demand were considered by some authors, such as Goswami and Chaudhari (1998), Kar et al. (2001), etc.

Yang (2004) provided a two-warehouse inventory model for a single item with constant demand and shortages under inflation. Zhou and Yang (2005) studied stock-dependent demand without shortage and deterioration with quantity-based transportation cost. Wee et al. (2005) considered a two-warehouse model with constant demand and Weibull distribution deterioration under inflation. Yang (2006) extended Yang (2004) to incorporate partial backlogging and then compared the two-warehouse models based on the minimum cost approach. Dye et al. (2007) developed a deterministic inventory model for deteriorating items with capacity constraint and backlogging rate. Singh et al. (2008) provided a two-warehouse inventory model for deteriorating items where shortages were allowed and partially backlogged.

Singh et al. (2009) offered a two-warehouse inventory model for deteriorating items with shortages. Jaggi et al. (2010) presented inventory and pricing strategies for deteriorating items with limited capacity and time-proportional backlogging rate. Panda et al. (2010) presented two warehouse inventory models for single vendor multiple retailers with price and stock dependent demand. Singh et al. (2011-a, 2011-b) developed a two-warehouse inventory models in different environment. Das et al. (2012) presented two-warehouse production model for deteriorating inventory items with stockdependent demand. Guchhait et al. (2013) developed two storage inventory model of a deteriorating item with variable demand under partial credit period without shortages.

Companies have recognized that in addition to maximizing profit, customer satisfaction plays an important role for getting and keeping a successful position in a competitive market. The proper inventory level should be set based on the relationship between the investment in inventory and the service level. With a lost sale, the customer's demand for the item is lost and presumably filled by a competitor. It can be considered as the loss of profit on the sales. Moreover, it also includes the cost of losing the customer, loss of goodwill, and of establishing a poor record of service. Therefore, if we omit the stockout cost from the total profit, then the profit will be overrated. It is true that the stockout cost is very difficult to measure. However, this does not mean that the unit does not have some specific values. In practice, the stockout cost can be easy to obtain from accounting data. In this paper, we develop a deterministic inventory model for deteriorating items with two warehouses. We assume that the inventory costs in RW are higher than those in OW. In addition, shortages are allowed in the owned warehouse and the backlogging rate of unsatisfied demand is assumed to be a decreasing function of 
the waiting time. We then prove that the optimal replenishment policy not only exists but also is unique. Moreover, a numerical example is used to illustrate the proposed model, and concluding remarks are provided.

In this paper, an attempt has been made to extend the model of Dye and Ouyang (2005) with a view to making the model more flexible, realistic and applicable in practice. Here, objectives are to maximize the profit and minimize the total shortage cost. In this model, fuzzy goals are used by linear membership functions and after fuzzification; it is solved by weighted fuzzy non-linear programming technique.

\section{The proposed model}

\subsection{Notations and modeling assumptions}

In this section, we give the notations and assumptions used throughout this paper:

1. The inventory system involves only one item.

2. The replenishment rate is infinite and lead-time is zero.

3. The owned warehouse (OW) has a fixed limited capacity of W units.

4. The rented warehouse (RW) has unlimited capacity.

5. The inventory holding costs (including holding and deterioration cost) in RW are higher than those in OW.

6. $\mathrm{I}_{0}(\mathrm{t})$ is the inventory level in $\mathrm{OW}$ at time $\mathrm{t}$.

7. $\mathrm{I}_{1}(\mathrm{t})$ is the inventory level in RW at time $\mathrm{t}$.

8. $\theta$ is the deterioration rate in $\mathrm{OW}$ and $\mathrm{RW}$, where $0<\theta<1$.

9. $\mathrm{A}$ is the ordering cost per unit per unit time.

10. $\mathrm{C}_{0}$ is the inventory holding cost per unit per unit time in OW.

11. $C_{R}$ is the inventory holding cost per unit per unit time in $R W$.

12. $\mathrm{p}$ is the selling price per unit per unit time.

13. $\mathrm{R}$ is the opportunity cost.

14. $\mathrm{Q}$ is the ordering quantity over the replenishment cycle.

15. Shortages are allowed and backlogged rate is defined to be $\frac{1}{1+\delta(T-t)}$. Shortage cost is $\mathrm{C}_{2}$ per unit per unit time and $\mathrm{R}$ is the fixed opportunity cost of lost sales per unit.

16. The demand rate $\mathrm{D}(\mathrm{p}, \mathrm{I}(\mathrm{t}))$, is dependent on selling price and displayed stock level in the show room with in the stock level $S_{0}$ to $S_{1}$ and beyond this range, it becomes constant with respect to the display stock level. The functional $\mathrm{D}(\mathrm{p}, \mathrm{I}(\mathrm{t}))$ is given by

$$
D(p, I(t))=\left\{\begin{array}{lrr}
a p+\beta S_{1} & I(t) \geq S_{1} \quad, 0 \leq t \leq t_{1} \\
a p+\beta I(t) & S_{o} \leq I(t) \leq S_{1}, t_{1} \leq t \leq t_{2} \\
a p & 0 \leq I(t) \leq S_{o} & , t_{2} \leq t \leq t_{3} \\
\frac{a p}{1+\delta(T-t)} & I(t) \leq 0 & , t_{3} \leq t \leq T
\end{array}\right.
$$

where, $\beta$ is a non-negative constant. a $\mathrm{p}$ is a non-negative function of selling price $\mathrm{p}$. 
17. $\mathrm{T}$ is the cycle time.

18. TP and SC respectively denote the total profit and total cost per unit per time.

\subsection{Mathematical formulation of the model}

At the beginning of the order cycle, the inventory level is raised to $Q$ afterwards as time progresses it is depleted by combined effects of the demand and deterioration. Using above assumptions, the inventory level follows the pattern depicted in Fig. 1. To establish the total relevant profit function, we consider the following time intervals separately, $\left[0, t_{1}\right],\left[t_{1}, t_{2}\right],\left[t_{2}, t_{3}\right]$ and $\left[t_{3}, T\right]$. During the interval $\left[0, t_{1}\right]$, the inventory levels are positive at $R W$ and $O W$. At $R W$, the inventory is depleted due to be the combined effects of demand and deterioration. At $O W$, the inventory is only depleted by the effect of deterioration. Hence, the inventory level at $R W$ and $O W$ are governed by the following differential equations:

\section{Inventory level}

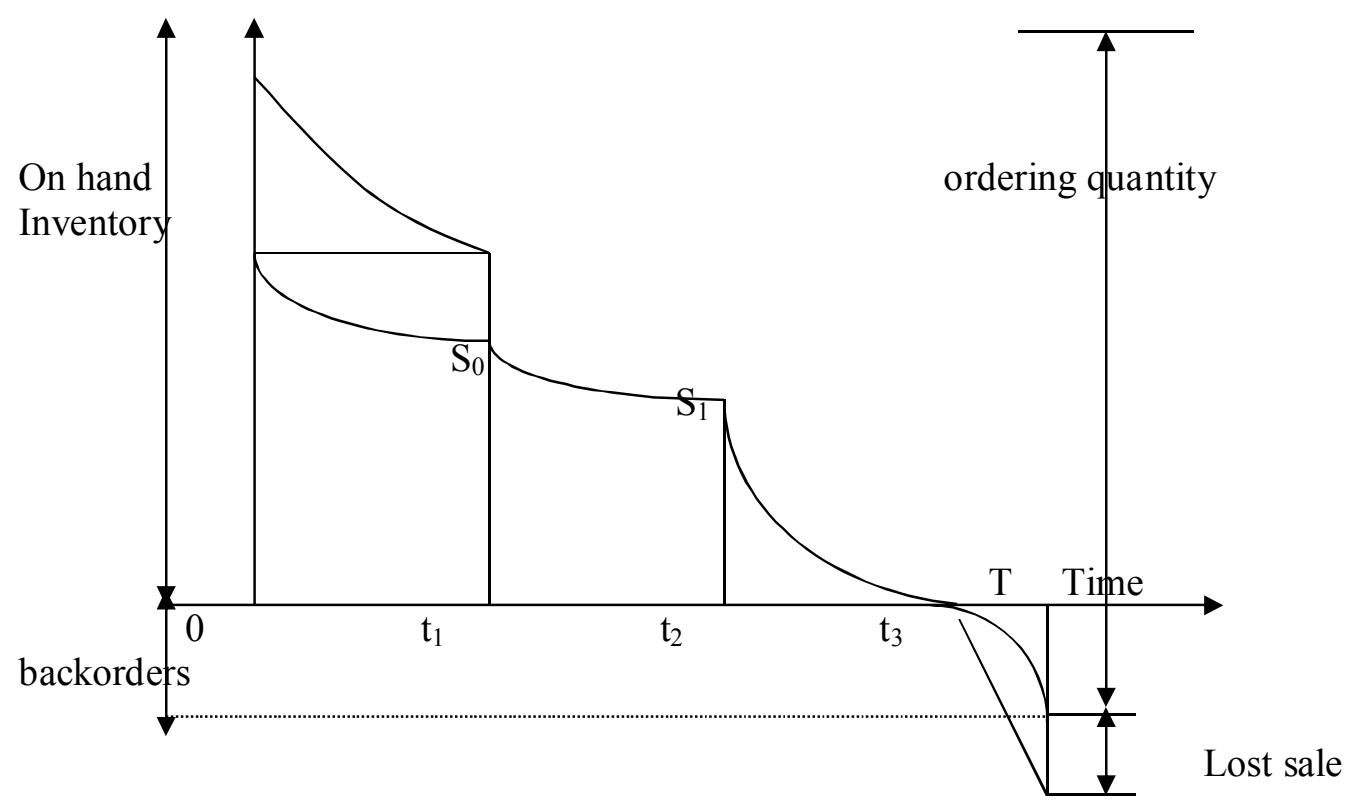

Fig.1. Graphical representation of a two-warehouse inventory system

Therefore, the differential equation governing the system for $R W$ and $O W$ during the period $(0 \leq t \leq T)$ can be written as:

$$
\begin{array}{lll}
\frac{d I_{R}(t)}{d t}+\theta I_{R}(t)=-\left(a p+\beta S_{1}\right), & & 0 \leq t \leq t_{1} \\
\frac{d I_{0}(t)}{d t}=-\theta I_{0}(t), & I_{0}(t) \geq S_{1}, & 0 \leq t \leq t_{1} \\
\frac{d I_{0}(t)}{d t}+\theta I_{0}(t)=-\left(a p+\beta I_{0}(t)\right), & S_{0} \leq I_{0}(t) \leq S_{1}, & t_{1} \leq t \leq t_{2} \\
\frac{d I_{0}(t)}{d t}+\theta I_{0}(t)=-(a p), & 0 \leq I_{0}(t) \leq S_{0}, & t_{2} \leq t \leq t_{3} \\
\frac{d I_{0}(t)}{d t}=-\frac{a p}{1+\delta(T-t)}, & I_{0}(t) \leq 0, & t_{3} \leq t \leq T
\end{array}
$$


The solutions of the above differential equations, after applying boundary conditions $I_{R}\left(t_{1}\right)=0$, $I_{0}\left(t_{1}\right)=S_{1}, I_{0}\left(t_{2}\right)=S_{0}$ and $I_{0}\left(t_{3}\right)=0$ are

$$
\begin{array}{lrl}
I_{R}(t)=-\left(\frac{a p+\beta S_{1}}{\theta}\right)\left(1-e^{\theta\left(t_{1}-t\right)}\right), & 0 \leq t \leq t_{1} \\
I_{0}(t)=S_{1} e^{\theta\left(t_{1}-t\right)}, & 0 \leq t \leq t_{1} \\
I_{0}(t)=S_{0} e^{(\beta+\theta)\left(t_{2}-t\right)}+\frac{a p}{(\beta+\theta)}\left(e^{(\beta+\theta)\left(t_{2}-t\right)}-1\right), & t_{1} \leq t \leq t_{2} \\
I_{0}(t)=\frac{a p}{\theta}\left(e^{\theta\left(t_{3}-t\right)}-1\right), & t_{2} \leq t \leq t_{3} \\
I_{0}(t)=\frac{a p}{\delta}\left\{-\operatorname{In}\left[1+\delta\left(T-t_{3}\right)\right]+\operatorname{In}[1+\delta(T-t)]\right\}, & t_{3} \leq t \leq T
\end{array}
$$

With the help of equations from Eq. (6) to Eq. (10), we calculate the following costs:

1. Ordering cost per cycle $=\mathrm{A}$

2. Holding cost in $O W$ per cycle

$$
\begin{aligned}
& \mathrm{HC}_{\mathrm{OW}}=C_{0}\left[\int_{0}^{t_{1}} I_{0}(t) d t+\int_{t_{1}}^{t_{2}} I_{0}(t) d t+\int_{t_{2}}^{t_{3}} I_{0}(t) d t\right] \\
& =C_{0}\left[\int_{0}^{t_{1}} S_{1} e^{\theta\left(t_{1}-t\right)} d t+\int_{t_{1}}^{t_{2}} S_{0} e^{(\beta+\theta)\left(t_{2}-t\right)}+\frac{a p}{(\beta+\theta)}\left(e^{(\beta+\theta)\left(t_{2}-t\right)}-1\right) d t+\int_{t_{2}}^{t_{3}} \frac{a p}{\theta}\left(e^{\theta\left(t_{3}-t\right)}-1\right) d t\right] \\
& =C_{0}\left[\frac{S_{1}}{\theta}\left(e^{\theta t_{1}}-1\right)+\frac{S_{0}}{(\beta+\theta)}\left(e^{(\beta+\theta)\left(t_{2}-t_{1}\right)}-1\right)+\frac{a p}{(\beta+\theta)^{2}}\left(e^{(\beta+\theta)\left(t_{2}-t_{1}\right)}-(\beta+\theta)\left(t_{2}-t_{1}\right)-1\right)\right. \\
& \left.+\frac{a p}{\theta^{2}}\left(e^{\theta\left(t_{3}-t_{2}\right)}-\theta\left(t_{3}-t_{2}\right)-1\right)\right]
\end{aligned}
$$

3. Holding cost in $R W$ per cycle

$$
\mathrm{HC}_{\mathrm{RW}}=C_{R} \int_{0}^{t_{1}} I_{R}(t) d t=C_{R} \int_{0}^{t_{1}}-\left(\frac{a p+\beta S_{1}}{\theta}\right)\left(1-e^{\theta\left(t_{1}-t\right)}\right) d t=C_{R} \frac{\left(a p+\beta S_{1}\right)}{\theta^{2}}\left(e^{\theta t_{1}}-\theta t_{1}-1\right)
$$

4. Shortage cost per cycle

$$
\begin{aligned}
& \mathrm{SC}=C_{2} \int_{t_{3}}^{T}-I_{0}(t) d t=C_{2} \int_{t_{3}}^{T}-\frac{a p}{\delta}\left\{-\operatorname{In}\left[1+\delta\left(T-t_{3}\right)\right]+\operatorname{In}[1+\delta(T-t)]\right\} d t \\
& =C_{2} \frac{a p}{\delta^{2}}\left\{\delta\left(T-t_{3}\right)-\operatorname{In}\left[1+\delta\left(T-t_{3}\right)\right]\right\}
\end{aligned}
$$

5. Opportunity cost due to lost sales per cycle

$$
\mathrm{OP}=\operatorname{apR} \int_{t_{3}}^{T}\left\{1-\frac{1}{1+\delta(T-t)}\right\} d t=\frac{a p R}{\delta}\left\{\delta\left(T-t_{3}\right)-\operatorname{In}\left[1+\delta\left(T-t_{3}\right)\right]\right\}
$$

6. Purchase cost per cycle $=C Q$, where $Q$ is the ordering quantity over the replenishment cycle 


$$
C Q=C\left[\frac{\left(a p+\beta S_{1}\right)}{\theta}\left(e^{\theta t_{1}}-1\right)+S_{1} e^{\theta t_{1}}+\frac{a p}{\delta} \operatorname{In}\left[1+\delta\left(T-t_{3}\right)\right]\right]
$$

7. Sales revenue per cycle

$$
\begin{aligned}
& \mathrm{SR}=S\left[\int_{0}^{t_{1}}\left(a p+\beta S_{1}\right) d t+\int_{t_{1}}^{t_{2}}\left(a p+\beta I_{0}(t)\right) d t+\int_{t_{2}}^{t_{3}} a p d t+\int_{t_{3}}^{T} \frac{a p}{1+\delta\left(T-t_{3}\right)} d t\right] \\
& =S\left[\left(a p+\beta S_{1}\right) t_{1}+a p\left(t_{2}-t_{1}\right)+\beta\left(\frac{S_{0}}{\beta+\theta}\left(e^{(\beta+\theta)\left(t_{2}-t_{1}\right)}-1\right)+\frac{a p}{(\beta+\theta)^{2}}\left(e^{(\beta+\theta)\left(t_{2}-t_{1}\right)}-(\beta+\theta)\left(t_{2}-t_{1}\right)-1\right)\right)\right. \\
& \left.\quad+a p\left(t_{3}-t_{2}\right)+\frac{a p\left(T-t_{3}\right)}{1+\delta\left(T-t_{3}\right)}\right]
\end{aligned}
$$

Total profit per unit time TP becomes:

$\mathrm{TP}=1$ [sales revenue - ordering cost - holding cost - shortage cost - opportunity - Purchase cost]/T

$$
\begin{aligned}
T P= & \frac{1}{T}\left\{S \left[\left(a p+\beta S_{1}\right) t_{1}+a p\left(t_{2}-t_{1}\right)+\beta\left(\frac{S_{0}}{\beta+\theta}\left(e^{(\beta+\theta)\left(t_{2}-t_{1}\right)}-1\right)+\frac{a p}{(\beta+\theta)^{2}}\left(e^{(\beta+\theta)\left(t_{2}-t_{1}\right)}-(\beta+\theta)\left(t_{2}-t_{1}\right)-1\right)\right)\right.\right. \\
+ & \left.a p\left(t_{3}-t_{2}\right)+\frac{a p\left(T-t_{3}\right)}{1+\delta\left(T-t_{3}\right)}\right]-A-C_{0}\left[\frac{S_{1}}{\theta}\left(e^{\theta t_{1}}-1\right)+\frac{S_{0}}{(\beta+\theta)}\left(e^{(\beta+\theta)\left(t_{2}-t_{1}\right)}-1\right)+\frac{a p}{(\beta+\theta)^{2}}\left(e^{(\beta+\theta)\left(t_{2}-t_{1}\right)}-\right.\right. \\
& \left.\left.(\beta+\theta)\left(t_{2}-t_{1}\right)-1\right)+\frac{a p}{\theta^{2}}\left(e^{\theta\left(t_{3}-t_{2}\right)}-\theta\left(t_{3}-t_{2}\right)-1\right)\right]-C_{R} \frac{\left(a p+\beta S_{1}\right)}{\theta^{2}}\left(e^{\theta t_{1}}-\theta t_{1}-1\right)-\frac{C_{2} a p}{\delta^{2}}\left\{\delta\left(T-t_{3}\right)-\right. \\
& \left.\left.\operatorname{In}\left[1+\delta\left(T-t_{3}\right)\right]\right\}-\frac{a p R}{\delta}\left\{\delta\left(T-t_{3}\right)-\operatorname{In}\left[1+\delta\left(T-t_{3}\right)\right]\right\}-C\left[\frac{\left(a p+\beta S_{1}\right)}{\alpha}\left(e^{\alpha t_{1}}-1\right)+S_{1} e^{\theta t_{1}}+\frac{a p}{\delta} \operatorname{In}\left[1+\delta\left(T-t_{3}\right)\right]\right]\right\}
\end{aligned}
$$

and total shortage cost per unit time

$$
S C=C_{2} \int_{t_{3}}^{T} \frac{a p}{\delta}\left\{\operatorname{In}\left[1+\delta\left(T-t_{3}\right)\right]-\operatorname{In}[1+\delta(T-t)]\right\} d t / T
$$

Where $\mathrm{S}_{0}$ and $\mathrm{S}_{1}$ is given by

$$
\begin{aligned}
& S_{1}=-\frac{a p}{(\beta+\theta)}+\left(S_{0}+\frac{a p}{(\beta+\theta)}\right) e^{(\beta+\theta)\left(t_{2}-t_{1}\right)} \\
& S_{0}=\frac{a p}{\theta}\left(e^{\theta\left(t_{3}-t_{2}\right)}-1\right)
\end{aligned}
$$

Now from Eq. (19) and Eq. (20), we get-

$$
\begin{aligned}
& t_{2}=t_{1}+\frac{1}{(\beta+\theta)} \operatorname{In}\left[\frac{S_{1}+\frac{a p}{(\beta+\theta)}}{S_{0}+\frac{a p}{(\beta+\theta)}}\right], \\
& t_{3}=t_{2}+\frac{1}{\theta} \operatorname{In}\left[\frac{S_{0}+\frac{a p}{\theta}}{\frac{a p}{\theta}}\right] .
\end{aligned}
$$

The above two equations implies $t_{1}-t_{2} \geq 0$ and $t_{3}-t_{2} \geq 0$ and the initial lot size 
$Q=I_{R}(0)+I_{0}(0)=S_{1} e^{\theta t_{1}}+\frac{\left(a p+\beta S_{1}\right)}{\theta}\left(e^{\theta t_{1}}-1\right)$

\subsection{Crisp model}

In crisp environment multi-objective problem of maximizing total profit and minimizing the total shortage cost can be written as follows,

$$
\begin{gathered}
\max \quad \mathrm{TP} \\
\min \mathrm{SC} \\
\text { subject to } \\
t_{1}-t_{2}>0 \\
t_{3}-t_{2}>0 \\
t_{1}, t_{2}, t_{3}, T \geq 0 .
\end{gathered}
$$

\subsection{Fuzzy model}

Since seller's maximum average revenue and minimum total shortage cost per unit time becomes imprecise in nature, the above model in fuzzy sense can be represented as:

$$
\begin{gathered}
\widetilde{\max } \quad \mathrm{TP} \\
\widetilde{m i n} \quad \mathrm{SC} \\
\text { Subject to } \\
t_{1}-t_{2}>0 \\
t_{3}-t_{2}>0 \\
t_{1}, t_{2}, t_{3}, T \geq 0 .
\end{gathered}
$$

\subsection{Fuzzy goal programming of model}

The fuzzy multi-objective problem can be formulated as a FNLGP as follows:

Find $\left(t_{1}, t_{2}, t_{3}, T\right)^{T}$

subject to

$$
\begin{gathered}
f_{1}\left(t_{1}, t_{2}, t_{3}, T\right)=-T P \leq-f_{01} \\
f_{2}\left(t_{3}, T\right)=S C \leq f_{02} \\
t_{1}-t_{2}>0 \\
t_{3}-t_{2}>0 \\
t_{1}, t_{2}, t_{3}, T \geq 0 .
\end{gathered}
$$

Here, the fuzzy goal of objectives, i.e. total average profit and total shortage cost, are $\left(f_{01}-P_{01}, f_{01}\right)$ and $\left(\mathrm{f}_{02}+\mathrm{P}_{02}, \mathrm{f}_{02}\right)$ respectively, and there linear MFs are consider as follows:

$$
\mu\left(f_{1}\left(t_{1}, t_{2}, t_{3}, T\right)\right)= \begin{cases}0, & \text { for } f_{1}\left(t_{1}, t_{2}, t_{3}, T\right) \leq-f_{01}+P_{01} \\ 1-\frac{f_{1}\left(t_{1}, t_{2}, t_{3}, T\right)+f_{01}}{P_{01}}, & \text { for }-f_{01} \leq f_{1}\left(t_{1}, t_{2}, t_{3}, T\right) \leq-f_{01}+P_{01} \\ 1, & \text { for } f_{1}\left(t_{1}, t_{2}, t_{3}, T\right) \leq-f_{01}\end{cases}
$$

i.e. 


$$
\begin{aligned}
& \mu_{1}(T P)= \begin{cases}0, & \text { for } T P \leq f_{01}-P_{01} \\
1+\frac{T P-f_{01}}{P_{01}}, & \text { forf } f_{01}-P_{01} \leq T P \leq f_{01} \\
1, & \text { for } T P \geq f_{01}\end{cases} \\
& \mu_{2}(S C)= \begin{cases}0, & \text { for } S C \geq f_{02}+P_{02} \\
1+\frac{S C-f_{02}}{P_{02}}, & \text { for } f_{02} \leq S C \leq f_{02}+P_{02} \\
1, & \text { for } S C \leq f_{01}\end{cases}
\end{aligned}
$$

Using the weights to respect different importance objectives, the problem can be written as follows,

$$
\begin{aligned}
& \max F=w_{1} \mu_{1}(T P)+w_{2} \mu_{2}(S C) \\
& \text { subject to } \\
& f_{01}-P_{01} \leq \mu_{1}(T P) \leq f_{01}, \\
& f_{02} \leq \mu_{2}(S C) \leq f_{02}+P_{02}, \\
& t_{1}-t_{2}>0 \\
& t_{3}-t_{2}>0 \\
& w_{1}+w_{2}=0 \\
& t_{1}, t_{2}, t_{3}, T \geq 0 .
\end{aligned}
$$

\section{Numerical examples}

To illustrate the above inventory model, values of the system parameters are considered as: $\mathrm{A}=250, \mathrm{C}$ $=5, \mathrm{i}=0.35, \mathrm{C}_{2}=3, \mathrm{p}=7, \mathrm{R}=5, \beta=0.3, \theta=0.8, \delta=10, \mathrm{~K}=20000, \mathrm{~S}_{0}=100, \mathrm{~S}_{1}=300, \mathrm{r}=1.5, \mathrm{f}_{01}=$ $-750, \mathrm{f}_{02}=30, \mathrm{P}_{01}=-625, \mathrm{P}_{02}=20$.

The optimal values of $t_{1}, t_{2}, t_{3}$ and $t_{4}$ along with total profit, total shortage cost and lost - size are displayed Table 1 and Table 2 as follows

Table 1

Results for Crisp model

\begin{tabular}{cccc}
\hline Crisp model & $\begin{array}{c}\text { Equal weight for profit } \\
\text { \& shortage cost }\end{array}$ & First priority for profit & $\begin{array}{c}\text { First priority for } \\
\text { shortage cost }\end{array}$ \\
\hline $\mathrm{t}_{1}$ & 0.2367 & 0.2421 & 0.2533 \\
$\mathrm{t}_{2}$ & 0.5013 & 0.5218 & 0.4912 \\
$\mathrm{t}_{3}$ & 0.6922 & 0.7027 & 0.7120 \\
$\mathrm{~T}$ & 0.9592 & 0.9738 & 0.9423 \\
Profit & 682.36 & 698.34 & 593.14 \\
Shortage cost & 55.31 & 61.39 & 50.38 \\
\hline Lot - size & 538.48 & 541.87 & 550.39 \\
\hline
\end{tabular}

According to results of Table 1 and Table 2, it is observed that when a seller takes care of his profit only, the seller makes maximum revenue at the cost of his reputation and goodwill. Similarly, when the seller only takes care of his shortage cost, his total revenue is lower. As expected, when interests of both seller's total revenue and shortage cost are considered, the total revenue and shortage costs become moderate, i.e., it lies between the above mentioned levels. 
Table 2

Results for Fuzzy model

\begin{tabular}{cccc}
\hline Crisp model & $\begin{array}{c}\text { Equal weight for profit } \\
\text { \& shortage cost }\end{array}$ & First priority for profit & $\begin{array}{c}\text { First priority for } \\
\text { shortage cost }\end{array}$ \\
\hline $\mathrm{t}_{1}$ & 0.2134 & 0.2346 & 0.2913 \\
$\mathrm{t}_{2}$ & 0.5139 & 0.5347 & 0.5820 \\
$\mathrm{t}_{3}$ & 0.7128 & 0.7368 & 0.7552 \\
$\mathrm{~T}$ & 0.9125 & 0.9524 & 0.9013 \\
Profit & 825.68 & 858.23 & 811.47 \\
Shortage cost & 41.56 & 49.26 & 24.68 \\
\hline Lot - size & 547.24 & 532.01 & 614.45 \\
\hline
\end{tabular}

\section{Conclusion}

In this paper, a two-warehouse inventory model has been developed for deteriorating items with finite warehouse capacity, permitting shortage and time-proportional backlogging rate. In this study, the demand was the combination of stock and price. Holding costs are different in OW and RW due to different preservation environments. To reduce the inventory costs, it will be economical for firms to store goods in OW before RW, but clear the stocks in RW before OW. In particular, the backlogging rate considered to be a decreasing function of the waiting time for the next replenishment is more realistic. In practice, we can observe periodically the proportion of demand which would accept backlogging and the corresponding waiting time for the next replenishment. Here, the main objectives are to maximize the profit and minimize the total shortage cost. In this model, fuzzy goals are used by linear membership functions and after fuzzification; it is solved by weighted fuzzy non-linear programming technique. From the numerical data, it is observed that when a seller takes care of his profit only, the seller makes maximum revenue at the cost of his reputation and goodwill. The proposed model can be extended in several ways. For instance, we may consider finite rate of replenishment. Also, we could extend the deterministic demand function to stochastic demand patterns. Furthermore, we could generalize the model to allow for permissible delay in payments.

\section{References}

Abad, P.L. (1996). Optimal pricing and lot sizing under conditions of perishability and partial backordering. Management Science, 42, 1093-1104.

Abad, P.L. (2001). Optimal price and order size for a reseller under partial backordering. Computers \& Operations Research, 28, 53-65.

Das, D., Kar, M.B., Roy, A., \& Kar, S. (2012). Two-warehouse production model for deteriorating inventory items with stock-dependent demand under inflation over a random planning horizon. Central European Journal of Operations Research, 20(2), 251-280.

Datta, T.K., Paul, K., \& Pal, A.K. (1998). Demand promotion by up-gradation under stock-dependent demand situation - a model. International Journal of Production Economics, 55(1), 31-38.

Dave, U. (1988). On the EOQ models with two levels of storage. Opsearch, 25, 190-196.

Dye, C.Y. (2002). A deteriorating inventory model with stock-dependent demand and partial backlogging under conditions of permissible delay in payment. Opsearch, 39, 3(4), 189-201.

Dye, C.Y., \& Ouyang, L.Y. (2005). An EOQ model for perishable items under stock-dependent selling rate and time dependent partial backlogging. European Journal of Operational Research, 163, $776-$ 783.

Dye, C.Y., Ouyang, L.Y., \& Hsieh, T.P. (2007). Deterministic inventory model for deteriorating items with capacity constraint and time-proportional backlogging rate. European Journal of Operational Research, 178(3), 789-807. 
Fathollah Bayati, M., Rasti Barzoki, M., \& Hejazi, S. R. (2011). A joint lot-sizing and marketing model with reworks, scraps and imperfect products.International Journal of Industrial Engineering Computations, 2(2), 395-408.

Goswami, A., \& Chaudhuri, K.S. (1998). On an inventory model with two levels of storage and stockdependent demand rate. International Journal of Systems Sciences, 29, 249-254.

Guchhait, P., Maiti, M.K., \& Maiti, M. (2013). Two storage inventory model of a deteriorating item with variable demand under partial credit period. Applied Soft Computing, 13 (1), 428-448.

Gupta, R., \& Vrat, P. (1986). Inventory model with multi-items under constraint systems for stock dependent consumption rate. Operations Research, 24(1), 41-42.

Hartley, R. V. (1976). Operations Research-A Managerial Emphasis, Good Year Publishing Company, California, 315-317.

Jaggi, C.K., Aggarwal, K.K., \& Verma, P. (2010). Inventory and pricing strategies for deteriorating items with limited capacity and time-proportional backlogging rate. International Journal of Operational Research, 8(3), 331-354.

Kar, S., Bhunia, A.K., \& Maiti, M. (2001). Deterministic inventory model with two levels of storage, a linear trend in demand and a fixed time horizon. Computers \& Operations Research, 28, 13151331.

Levin, R.I., McLaughlin, C.P., Lamone, R.P., \& Kottas, J.F. (1972). Productions Operations Management: Contemporary Policy for Managing Operating Systems, pp.373, McGraw-Hill, New York.

Mandal, B.N., \& Phaujdar, S. (1989). An inventory model for deteriorating items and stock-dependent consumption rate. Journal Operational Research Society, 40(5), 483-488.

Muluneh, E.K., \& Rao, K.S. (2012). EPQ models for deteriorating items with stock-dependent production rate and time-dependent demand having three-parameter Weibull decay. International Journal of Operational Research, 14(3), 271-300.

Murdeshwar, T.A., \& Sathe, Y.S. (1985). Some aspects of lot size model with two levels of storage, Opsearch, 22, 255-262.

Pakkala, T.P.M., \& Achary, K.K. (1992). A deterministic inventory model for deteriorating items with two warehouses and finite replenishment rate. European Journal of Operational Research, 57, 7176.

Pakkala, T.P.M., \& Achary, K.K. (1992). Discrete time inventory model for deteriorating items with two warehouses. Opsearch, 29, 90-103.

Panda, D., Maiti, M.K., \& Maiti, M. (2010). Two warehouse inventory models for single vendor multiple retailers with price and stock dependent demand. Applied Mathematical Modelling, 34 (11), $3571-3585$.

Sarma, K.V.S. (1987). A deterministic order level inventory model for deteriorating items with two storage facilities. European Journal of Operational Research, 29, 70-73.

Sarma, K.V.S. (1983). A deterministic inventory model with two level of storage and an optimum release rule. Opsearch, 20, 175-180.

Singh, S.R., Kumar, N., \& Kumari, R. (2008). Two-Warehouse inventory model for deteriorating items with partial backlogging under the conditions of permissible delay in payments. International Transactions in Mathematical Sciences \& Computer, 1(1), 123-134.

Singh, S.R., Kumar, N., \& Kumari, R. (2009). Two-warehouse inventory model for deteriorating items with shortages under inflation and time-value of money. International Journal of Computational and Applied Mathematics, 4(1), 83-94.

Singh, S.R., Kumar, N., \& Kumari, R. (2010). An inventory model for deteriorating items with shortages and stock-dependent demand under inflation for two-shops under one management. Opsearch, 47(4), 311-329.

Singh, S.R., Kumar, N., \& Kumari, R. (2010). An inventory model for deteriorating items with shortages and stock-dependent demand under inflation for two-shops under one management. Opsearch, 47(4), 311-329. 
Singh, S.R., Kumar, N., \& Kumari, R. (2011-a). Two-warehouse fuzzy inventory model under the conditions of permissible delay in payments. International Journal of Operational Research, 11(1), 78-99.

Singh, S.R., Kumari, R., \& Kumar, N. (2011-b). A deterministic two-warehouse inventory model for deteriorating items with sock-dependent demand and shortages under the conditions of permissible delay. International Journal of Mathematical Modelling and Optimization, 11(3), 357-375.

Taleizadeh, A. A., Cárdenas-Barrón, L. E., Biabani, J., \& Nikousokhan, R. (2012). Multi products single machine EPQ model with immediate rework process. International Journal of Industrial Engineering Computations, 3(2), 92-102.

Wee, H.M., Yu, J.C.P., \& Law, S.T. (2005). Two-warehouse inventory model with partial backordering and Weibull distribution deterioration under inflation. Journal of the Chinese Institute of Industrial Engineers, 22(6), 451-462.

Yang, H.L. (2004). Two-warehouse inventory models for deteriorating items with shortages under inflation. European Journal of Operational Research, 157, 344-356.

Yang, H.L. (2006). Two-warehouse partial backlogging inventory models for deteriorating items under inflation. International Journal Production Economics, 103(1), 362-370.

Zhou, Y.W., \& Yang, S.L. (2005). A two-warehouse inventory model for items with stock-leveldependent demand rate. International Journal Production Economics, 95(1), 215-228. 